\title{
Mahabaleshwar, Deccan Traps, India
}

The $~ 1,500-\mathrm{km}$-long Western Ghats (Sahyadri) great escarpment of India is a mountainous region of great scenic beauty, as well as a biodiversity hotspot. In its northern part, the escarpment is cut across the Deccan Traps flood basalt lavas of Late Cretaceous ( $\sim 65 \mathrm{Ma})$ age and forms the western precipitous edge of the Deccan Plateau. The town of Mahabaleshwar, situated here 1,436 m above sea level, is a popular tourist destination because of its scenic views and cool climate. The $>1,200$-m-thick Deccan flood basalt sequence exposed in the escarpment at Mahabaleshwar contains nearly fifty individual lava flows, with intervening red or green "bole" beds (too thin to be visible in this photograph). The sequence is capped by a regionally extensive ferricrete ("laterite") blanket several tens of meters thick. This photograph, taken from the viewpoint named Arthur's Seat $(1,347 \mathrm{~m})$ near Mahabaleshwar, shows a spectacular view of the sinuous and highly eroded Western Ghats escarpment, the thick, horizontally disposed lava sequence, and the flat and thickly forested ferricrete summits. The elevation difference between the summits and the lowest point in the valley in the foreground is $\sim 1,000 \mathrm{~m}$. Photograph by Hetu Sheth, Indian Institute of Technology Bombay (hcsheth@iitb.ac.in). More information: Ollier and Sheth (J. Earth Syst. Sci., v. 117, pp. 537-551, 2008) and references therein.

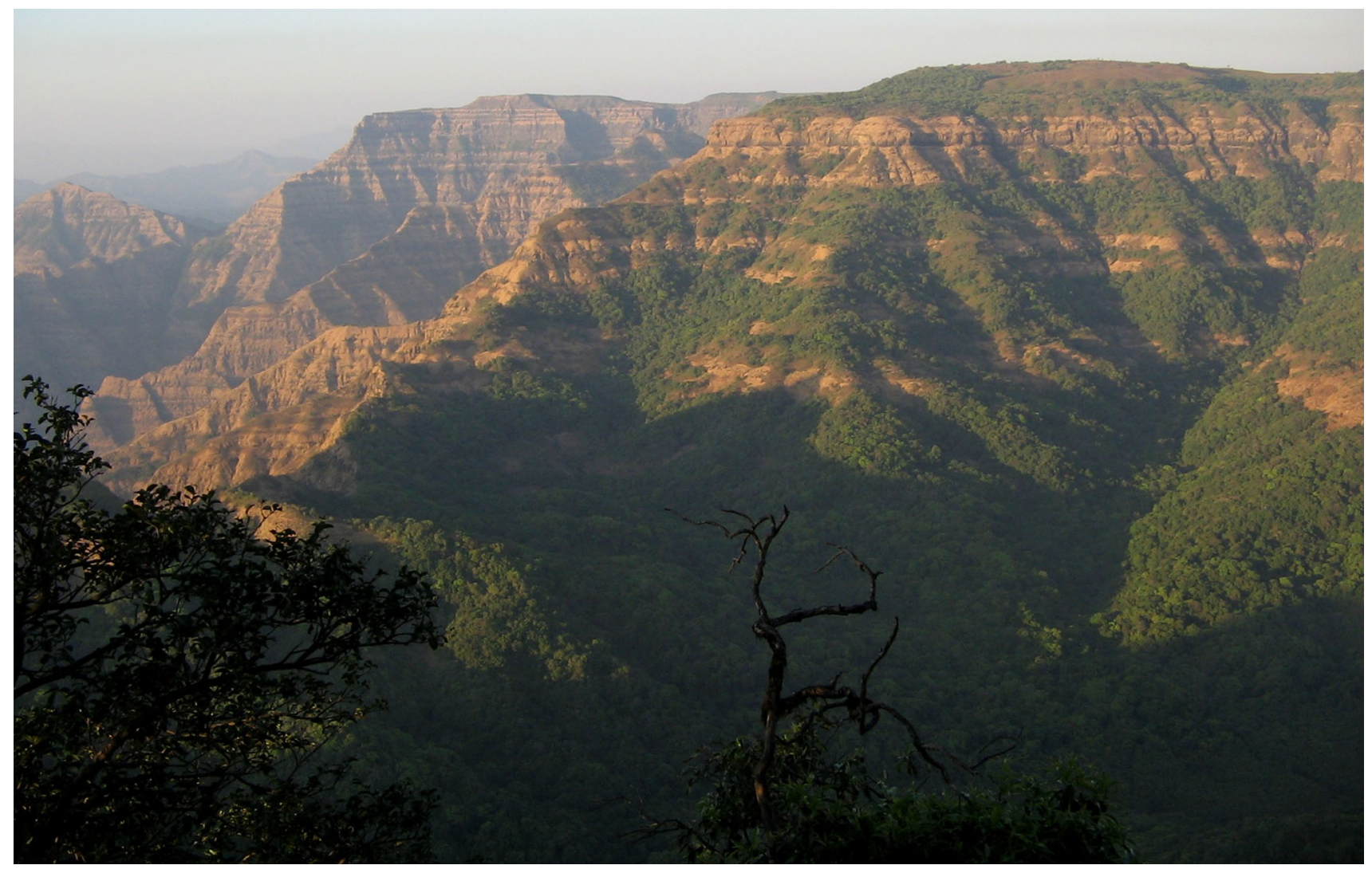

H. C. Sheth $(\bowtie)$

Mumbai, India

e-mail: hcsheth@iitb.ac.in

Received: 6 June 2013/Accepted: 14 July 2013/Published online: 3 August 2013

(c) Springer-Verlag Berlin Heidelberg 2013 